\title{
Investigation of community outbreak of enteric fever associated with drinking water in Borsad, Anand, Gujarat
}

\author{
Rashmi Sharma ${ }^{1}$ Harsh Bakshi ${ }^{2}$, Sachin Patel ${ }^{3}$, Manisha Panchal ${ }^{4}$, Gajjar Sanju ${ }^{5}$
}

${ }^{1}$ Associate Professor, Community Medicine Department, GMERS Medical College Sola, Ahmedabad, Gujarat; ${ }^{2}$ Assistant Professor, Community Medicine Department, GMERS Medical College Sola, Ahmedabad, Gujarat; ${ }^{3}$ Assistant Professor, Microbiology Department., GMERS Medical College Sola, Ahmedabad, Gujarat; ${ }^{4}$ Associate Professor, Medicine Department, GMERS Medical College, Himmatnagar; ${ }^{5}$ Tutor, Community Medicine Department, GMERS Medical College Sola, Ahmedabad, Gujarat

\begin{tabular}{|c|c|c|c|c|c|c|c|c|}
\hline Abstract & Introduction & Methodology & Results & Conclusion & References & Citation & \multicolumn{2}{|c|}{ Tables / Figures } \\
\hline \multicolumn{9}{|c|}{ orresponding Author } \\
\hline \multicolumn{8}{|c|}{$\begin{array}{l}\text { Dr Rashmi Sharma, Associate Professor, Community Medicine Department, GMERS Medical College Sola, } \\
\text { Ahmedabad, Gujarat } 380060 \\
\text { E Mail ID: } \underline{\text { drrashmi psm@yahoo.com }}\end{array}$} & 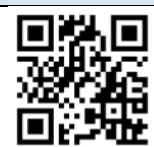 \\
\hline
\end{tabular}

\section{Citation}

Sharma R, Bakshi H, Patel S, Panchal M, Sanju G. Investigation of community outbreak of enteric fever associated with drinking water in Borsad, Anand, Gujarat. Indian J Comm Health. 2020;32(2):450-453.

Source of Funding: Nil Conflict of Interest: None declared

\section{Article Cycle}

Received: 01/05/2020; Revision: 17/05/2020; Accepted: 29/05/2020; Published: 30/06/2020

This work is licensed under a Creative Commons Attribution 4.0 International License.

\section{Abstract}

Background: Enteric fever is an endemic health problem and frequently associated with outbreaks. Objectives: Investigate sudden surge in gastroenteritis cases to confirm the outbreak, describe it in terms of time place and person, identify source of infection, modes of transmission and suggest remedial measures. Material \& Methodology: Field visit was undertaken by the rapid response team (RRT) at Borsad town of Anand district in Gujarat for investigating suspected typhoid outbreak. This involved gathering information from local authorities, hospital admissions and home visits; collection of blood samples and water samples. Result: Of 30 suspected cases, 19 (63.3\%) tested Widal positive. Common presenting symptoms were fever, vomiting followed by diarrhea and abdominal pain. Chlorine levels at source and end users were inadequate. 5 leakage points in water supply were identified in areas around the clustered cases. Conclusion and Recommendations: Leakage in piped water supply coupled with inadequate chlorination lead to contaminated drinking water and subsequent Typhoid epidemic. Corrective steps in form of rapid surveys to identify cases, household chlorination and appropriate engineering measures were recommended and implemented.

\section{Keywords}

Typhoid; Investigation of Epidemic; Rapid Response Team; Gastroenteritis; Chlorination

\section{Introduction}

Enteric Fever or Typhoid fever occurs in those parts of the world which have substandard water supply and poor sanitation. While Enterica serovar Typhi (S. Typhi) is the most common etiologic agent, cases due to $S$. Paratyphoid A (SPA) are on the rise.(1) In low-income countries it sickens millions of people each year.(2) India, with an incidence rate of 493.5 cases per 100,000 person-years, is endemic for the disease and shows higher incidence in regions where water supply is contaminated with faeces. $(3,4)$ In Gujarat, reported cases increased between 2010 and 2017 from approximately 10,000 to 46,000.(5) During the 7-year period (2005-11), for every 100,000 people in the state, approximately 186 reportedly suffered from enteric fever, with an average case rate of 26.7/100,000 population/year.(6) Morbidity and mortality due to Typhoid have increased since poor sanitation, lack of a safe drinking water supply and low socio-economic conditions in resource-poor countries are amplified by the evolution of multidrug resistant salmonellae leading to treatment failure and relapse. The ability to quickly recognize and respond to a disease outbreaks is a particular public health management challenge due to a variety of new pathogens, different risk factors (travel, food imports, technological innovation etc.), variable spread, increased public and media attention, economic and political consequences. (7) 


\section{Brief Demographic description of the affected district}

Borsad is Municipality town in the Anand district of Gujarat. It is located $17 \mathrm{~km}$ from district headquarters and has a population of 63,377 and sex ratio of 923 . Its average literacy rate $(68 \%)$ is higher than the national average (59.5\%).(8)

\section{Aims \& Objectives}

To investigate the sudden surge in gastroenteritis cases to confirm the outbreak, describe it in terms of time place and person, identify source of infection, modes of transmission and suggest remedial measures.

\section{Material \& Methods}

Following an intimation regarding increased reporting of acute gastroenteritis (AGE) cases from Borsad in Feb 2018, a Rapid Response Team (RRT) comprising of faculty from Community Medicine, Medicine, Microbiology from a Medical College of Ahmedabad city was deployed to investigate the epidemic. Background information and necessary data were provided by the health authorities. 30 odd cases were reported over a period of 10 days and were plotted on a spot map. Widal test was done for all 30 cases. Blood samples (4) were collected from newly admitted cases (yet not put on antibiotics) for culture and serum samples (7) for Anti HEV anti bodies. Two areas namely Fatepura and Saiyad tekra, where clustering of cases was seen were visited by the team for on the spot assessment. (Table2). 4 Water samples, 1 from bore well (supply end) and 3 from different localities with clustering of cases (user end) for were collected and analyzed for residual chlorine and faecal contamination. Structured questionnaire was used to collect information for admitted cases to interview and clinically assess for management and treatment. Other cases were contacted at their residences.

\section{Results}

Community Health Centre $(\mathrm{CHC})$ and Urban Health Centre (UHC) Borsad were located in the same premises and facilities were inadequate. No data of previous years was available for comparison. Following the Index case on 19/02/2018, within 9 days cases increased to 30 (on 01/03/2018). (Figure 1). The outbreak being in a Muslim locality, all 30 cases were among Muslims. Mean age of affected cases was $24.2 \pm 14.3$ years. Age and sex distribution of the cases is as shown in (Table 1). 19 $(63.3 \%)$ tested positive on Widal. Average time lag between appearance of symptoms and admission to the health facility was $4.2 \pm 1.3$ days. However, all patients were admitted to health facilities on the same day they tested positive. Common presenting symptoms were fever, vomiting followed by diarrhea, abdominal pain, chills, cough, muscular/ body/ joint pain or headache. No complications or deaths were reported. All cases were treated or being treated (at the time of investigation) either as indoor cases or on OPD basis. Distribution of cases and leakages in different localities is as shown in (Table 2) and (Figure 2). Clustering of cases was observed around points of leakages. Of the 7 sera samples examined later at tertiary care center, all were negative for Anti HEV antibodies and 2 were positive for Widal. All water samples, except 1 , taken in the community tested negative for chlorine. In one sample taken at user end, residual chlorine was $0.2 \mathrm{ppm}$. Community was not using any water purification methods and was unaware of role or correct method of use of these tablets. Personal hygiene was assessed in these patients by inquiring about hand washing with soap water before eating or after defecation and was found to be poor. Pumping station in the locality was visited for inspection. Chlorination was supposedly being done using liquid chlorine solution but the pump used for the same was not functioning properly. There was a log book to record the residual chlorine levels but it was never filled. Water sample collected from the bore well (supply end) was negative for residual chlorine. Out of 4 water samples collected from different localities, fecal contamination was found in 2 . The public health response by the local health department, supplemented by technical inputs from RRT, included:

1. OPD based management as per Standard Treatment guidelines,

2. Case confirmation by Widal test,

3. Identification of leakage (5 sewage broken oints)

4. Fever surveillance in "at risk neighborhood" for additional cases

5. Distribution of Chlorine tablets to all households in the area

6. Reporting of suspect cases by private practitioners ( 3 - 4 suspected cases were reported by a private practitioner from a nearby area).

\section{Discussion}

Investigation of any epidemic is always a challenge as much is to be achieved in a short time with limited resources. Though broad guidelines for epidemic investigations are available but disease specific guidelines are missing, hence such investigations are always a learning experience and such reports also act as reference points for future. An outbreak of acute diarrhoeal disease (57 cases) was recorded in a nearby village in June-July which was linked to food consumed at a festive gathering. Here too there was no residual chlorine in the water supply.(9) The current outbreak occurred due to contamination of drinking water due to leakage in sewer lines. Poor water quality and faecal contamination of drinking water resulting in outbreaks of typhoid fever have been reported previously in different parts of India as well. $(10,11,12,13,14)$ In Bholakpur, India, bacteriological pollution of drinking water due to infiltration of contaminated water through cross connection/ leaking points and back siphoning cause diarrheal illness.(15) In the current outbreak, very few 
children were affected, probably due to limited exposure. Also, higher female cases may be due to more time spent at home leading to increased exposure. Similar investigation in Jorhat, Assam; reported $78.5 \%$ children and young adults being affected.(10) Majority of the cases reported suffering from fever and diarrhea. Investigation by Misra et al also reported presence of fever as universal finding of all cases.(12) Due to changing modes of presentation and development of multidrug resistance (MDR), typhoid fever is becoming increasingly difficult to diagnose and treat. Laboratory confirmation and epidemiological linkage therefore become crucial. Knowledge and awareness regarding hygiene was poor as evident from non-usage of any household method of water purification except for using cloth to strain in a few households or heating the water (not rolling boil) and lack of hand hygiene among patients. The infrastructure and staffing at the $\mathrm{CHC} / \mathrm{UHC}$ were far from ideal and upgradation was required to efficiently deal with future challenges

\section{Conclusion}

Sudden surge in AGE was due to Typhoid outbreak due to contamination of community bore well water with leaked sewage. Chlorine levels at supply and user's end as well as knowledge and awareness regarding purification methods and hand hygiene were far from satisfactory.

\section{Recommendation}

Borsad, being an urban town needs a properly functioning Urban Health Centre. Authorities need to regularly ensure chlorination in the water distribution system. Behaviour change communication regarding personal hygiene and sanitation along with safe drinking water and waste disposal is required. Continued surveillance is required for the current outbreak since some cases might still be incubating. Regular maintenance and monitoring of the bore well, water and sewage lines should be undertaken, especially before monsoon, to prevent such outbreaks.

\section{Limitation of the study}

In the limited time and resources, population exposed could not be identified. Follow up of cases and their outcomes could not be done. Hence several epidemiological parameters could not be documented.

\section{Relevance of the study}

This article is intended to be a ready reckoner for a quick outbreak investigation. In absence of situation specific protocol and guidelines, this highlights some of the steps to be followed while investigating an outbreak.

\section{Authors Contribution}

RS: RRT Member, Epidemiological Investigation of Outbreak and Public health Recommendations, Manuscript writing. HB: RRT Member, Epidemiological Investigation of Outbreak and Public health Recommendations, Manuscript writing. SP: RRT Member,
Microbiological Investigation of Outbreak, Processing water and blood samples. MP: RRT Member, Clinical Investigation of Outbreak and Clinical Recommendations. GS: Data compilation, Manuscript writing

\section{Acknowledgement}

The authors acknowledge the Health Departments of the District and Municipality for their support and implementation.

\section{References}

1. Department of Vaccines and Biologicals. Geneva: WHO; 2003. World Health Organization. Background document: The diagnosis, treatment and prevention of typhoid fever. Communicable disease surveillance \& response; pp. 4-13.

2. Mogasale V, Maskery B, Ochiai RL, Lee JS, Mogasale VV, Ramani E, Kim YE, Park JK, Wierzba TF. Burden of typhoid fever in low-income and middle-income countries: a systematic, literature-based update with risk-factor adjustment. Lancet Glob Health. 2014 Oct;2(10):e570-80. doi: 10.1016/S2214-109X(14)70301-8. PubMed PMID: 25304633.[PubMed]

3. Roy JS, Saikia L, Medhi M, Tassa D. Epidemiological investigation of an outbreak of typhoid fever in Jorhat town of Assam, India. Indian J Med Res. 2016 Oct;144(4):592-596. doi: 10.4103/09715916.200902. PubMed PMID: 28256469; PubMed Central PMCID: PMC5345307.[PubMed]

4. Ochiai RL, Acosta CJ, Danovaro-Holliday MC, Baiqing D, Bhattacharya SK, Agtini MD, Bhutta ZA, Canh DG, Ali M, Shin S, Wain J, Page AL, Albert MJ, Farrar J, Abu-Elyazeed R, Pang T, Galindo CM, von Seidlein L, Clemens JD. A study of typhoid fever in five Asian countries: disease burden and implications for controls. Bull World Health Organ. 2008 Apr;86(4):260-8. doi: 10.2471/blt.06.039818. PubMed PMID: 18438514; PubMed Central PMCID: PMC2647431. [PubMed].

5. https://www.statista.com/statistics/861510/india-number-oftyphoid-cases-in-gujarat/

6. Iyer V, Azhar GS, Choudhury N, Dhruwey VS, Dacombe R, Upadhyay A. Infectious disease burden in Gujarat (2005-2011): comparison of selected infectious disease rates with India. Emerg Health Threats J. 2014;7:22838. doi: 10.3402/ehtj.v7.22838. eCollection 2014. PubMed PMID: 24647088; PubMed Central PMCID: PMC3962030.[PubMed]

7. Institute of medicine:Institute of Medicine. 2000. Public Health Systems and Emerging Infections: Assessing the Capabilities of the Public and Private Sectors: Workshop Summary. Washington, DC: The National Academies Press. https://doi.org/10.17226/9869.http://webcache.googleuserconte nt.com/search?q=cache:http://www.kdheks.gov/epi/Investigation _Guidelines/Typhoid_Fever_Disease_Investigation_Guideline.pdf \#9

8. Census of India 2001: Data from the 2001 Census, including cities, villages and towns (Provisional)". Census Commission of India. Archived from the original on 16 June 2004. Retrieved 1 November 2008

9. Nirav Patel, Akash Patel, Rahul Patel, Lakshmi N, Navin Raja Sekar, Rajshree Bhat. An Epidemiological Investigation of Acute Diarrhoeal Disease Outbreak in Sojitra Village of Anand District by Rapid Response Team of B. J. Medical College, Ahmedabad. Healthline Journal. 2017;8(2):60-64.

10. Roy JS, Saikia L, Medhi M, Tassa D. Epidemiological investigation of an outbreak of typhoid fever in Jorhat town of Assam, India. Indian J Med Res. 2016 Oct;144(4):592-596. doi: 10.4103/09715916.200902. PubMed PMID: 28256469; PubMed Central PMCID: PMC5345307.[PubMed].

11. Dhadwal BS, Shetty RA. Epidemiological Investigation of a Typhoid Outbreak. Med J Armed Forces India. 2008 Jul;64(3):241-2. doi: 10.1016/S0377-1237(08)80103-7. Epub 2011 Jul 21. PubMed 
INDIAN JOURNAL OF COMMUNITY HEALTH / VOL 32 / ISSUE NO 02 / APR - JUN 2020 PMID: 27408156; PubMed Central PMCID: PMC4921680.[PubMed].

12. Misra RN, Bawa KS, Magu SK, Bhandari S, Nagendra A, Menon PK. Outbreak of Multi-drug Resistant Salmonella Typhi Enteric Fever in Mumbai Garrison. Med J Armed Forces India. 2005 Feb;61(2):148 50. doi: 10.1016/S0377-1237(05)80011-5. Epub 2011 Jul 21. PubMed PMID: 27407737; PubMed Central PMCID: PMC4922961.[PubMed].

13. Banerjee A, Kalghatgi AT, Singh P, Nagendra A, Singh Z, Handa SK. Epidemiological Investigation of an Outbreak of Enteric Fever. Med J Armed Forces India. 2007 Oct;63(4):322-4. doi: 10.1016/S0377-
[Investigation of community...] | Sharma R et al 1237(07)80005-0. Epub 2011 Jul 21. PubMed PMID: 27408039; PubMed Central PMCID: PMC4921973.[PubMed]

14. Saha MR, Dutta P, Bhattacharya SK, Rasaily R, Mitra U, Dutta D, Bhattacharya MK, Pal SC. Occurrence of multi-drug resistant Salmonella typhi in Calcutta. Indian J Med Res. 1992 Jul;95:179-80. PubMed PMID: 1398805.[PubMed].

15. Abdul RM, Mutnuri L, Dattatreya PJ, Mohan DA. Assessment of drinking water quality using ICP-MS and microbiological methods in the Bholakpur area, Hyderabad, India. Environ Monit Assess. 2012 Mar;184(3):1581-92. doi: 10.1007/s10661-011-2062-2. Epub 2011 May 5. PubMed PMID: 21544503.[PubMed]

\section{Tables}

TABLE 1 AGE \& SEX WISE DISTRIBUTION OF LINE LISTED TYPHOID CASES ( $\mathrm{N}=30$ )

\begin{tabular}{|c|c|c|c|}
\hline Age (Years) & Male & Female & Total \\
\hline $\mathbf{0 0 - 0 5}$ & 0 & 2 & 2 \\
\hline $\mathbf{0 5 - 1 5}$ & 3 & 5 & $\mathbf{7}$ \\
\hline $\mathbf{1 5 - 2 5}$ & 3 & 4 & 9 \\
\hline $\mathbf{2 5}-\mathbf{4 5}$ & 2 & 7 & 3 \\
\hline $\mathbf{4 5 - 6 0}$ & 0 & 3 & 1 \\
\hline $\mathbf{2 6 0}$ & 0 & 1 & 30 \\
\hline Total & 8 & 22 & \\
\hline
\end{tabular}

TABLE 2 DISTRIBUTION OF CASES ( $=30$ ) AS PER THE LOCALITY AND THE LEAKAGE OBSERVED

\begin{tabular}{|l|l|l|}
\hline Area & No $(\%)$ & Leakage reported \\
\hline Jhupadpatti & $1(3.3)$ & Yes (2) \\
\hline Saiyad Tekra & $8(26.7)$ & Yes \\
\hline Rabari Chakla & $4(13.4)$ & No \\
\hline Rajofaliya & $3(10)$ & No \\
\hline Kantannagar & $1(3.3)$ & Yes \\
\hline Malekwada & $4(13.4)$ & No \\
\hline Bhoivas & $1(3.3)$ & No \\
\hline Madinanagar & $2(6.7)$ & Yes \\
\hline Fatehpura & $5(1.7)$ & No \\
\hline Vankarvas & $1(3.3)$ & \\
\hline
\end{tabular}

\section{Figures}

FIGURE 1 MAP OF STUDY AREA REPORTING LEAKAGES IN WATER SUPPLY AND NUMBER OF CASES
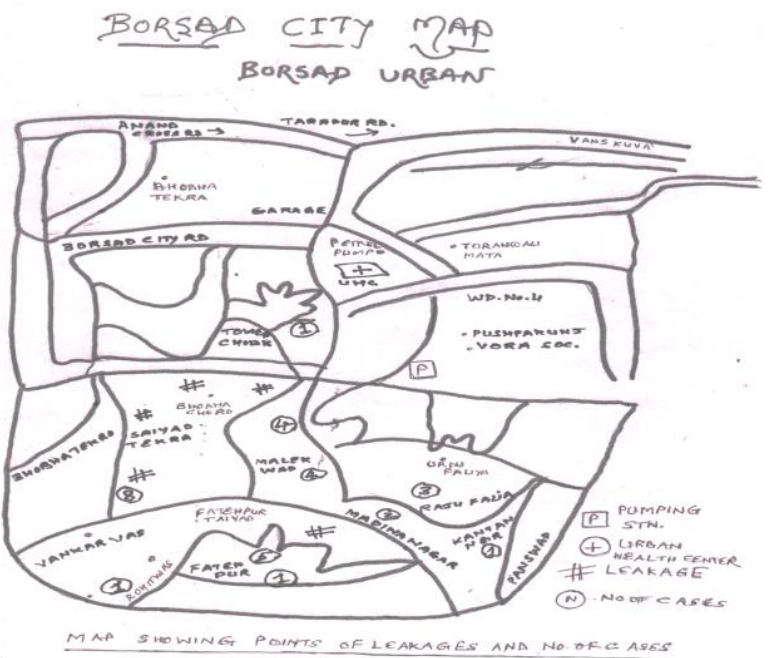

FIGURE 2 EPIDEMIC CURVE OF TYPHOID CASES FEBRUARY 2018

\section{Cases}

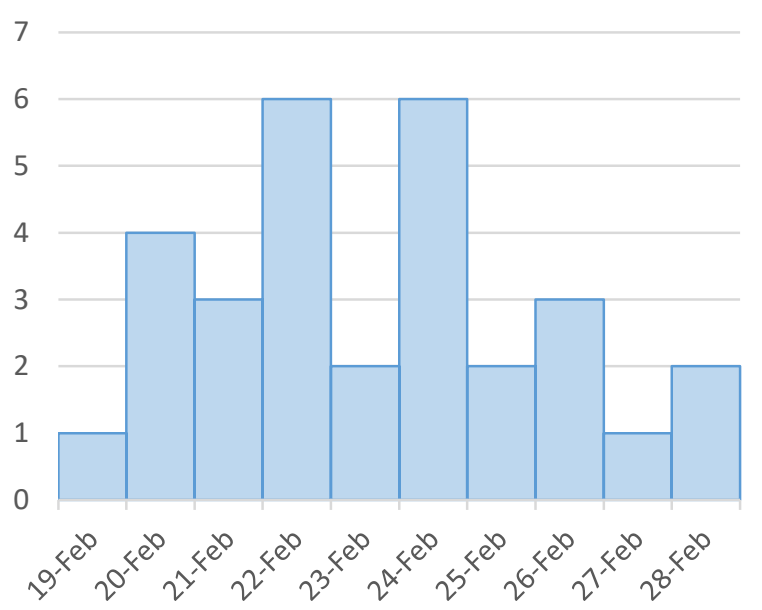

